\title{
Immunoproliferative Small Intestinal Disease with Protein Loss Complicated with Duodenal T Cell Lymphoma during Progression
}

\author{
Takeshi Hara ${ }^{1}$, Hisashi Tsurumi ${ }^{1}$, Tomohiro Kato ${ }^{1}$, Yasuyuki Imao ${ }^{1,2}$, Yasushi Kojima ${ }^{1}$, \\ Keishi Kojima ${ }^{1}$, Jun-ichi Kitagawa ${ }^{1}$, Naoki Katsumura ${ }^{2}$, Hiroshi Araki ${ }^{1}$, Tsuyoshi Takami ${ }^{3}$ \\ and Hisataka Moriwaki ${ }^{1}$
}

\begin{abstract}
A 52-year-old man was admitted to our hospital in October 2001 with abdominal pain. Abdominal X-ray indicated a diagnosis of ileus. Histopathological and immunological examination resulted in a diagnosis of immunoproliferative small intestinal disease (IPSID). He was treated with THP-COP therapy (pirarubicin, cyclophosphamide, vincristine, and prednisolone), which resulted in complete remission. Outpatient follow-up revealed hypoalbuminemia in May 2003 and upper gastrointestinal endoscopy showed duodenal mucosal nodularity. He was diagnosed with relapsed IPSID and salvage chemotherapy was started. Follow-up endoscopy confirmed that the therapy was effective, but uncovered another duodenal mucosal nodularity. Immunohistochemical staining revealed T-cell lymphoma. Chemotherapy was discontinued and the patient died in December 2004.
\end{abstract}

Key words: immunoproliferative small intestinal disease (IPSID), T-cell lymphoma, double cancer

(DOI: 10.2169/internalmedicine.47.0524)

\section{Introduction}

Immunoproliferative small intestinal disease (IPSID), also known as "Mediterranean" lymphoma of heavy chain disease, is characterized by a diffuse and intense plasma cell infiltrate in the lamina propria of the small intestine that can give rise to malignant lymphoma $(1,2)$. Generally, IPSID is considered a variant of mucosa-associated lymphoid tissue (MALT) lymphoma (3). In the recent WHO classification of hematopoietic and lymphoid tissue disorders, IPSID is listed with heavy chain disease as a special variant of extranodal marginal zone B-cell lymphoma (MALT) (4).

Since its initial description (5), IPSID has primarily been identified in the Mediterranean basin, the Middle East, the Far East and Africa. The most common site of extranodal lymphoma among Middle Eastern patients is the gastrointestinal tract and IPSID accounts for about one-third of gastro- intestinal lymphomas (6). However, IPSID appears to be rare in Japan (7). We describe a patient with IPSID who presented with bowel obstruction and complicated with duodenal $\mathrm{T}$ cell lymphoma over a 3-year clinical course.

\section{Case Report}

A 52-year-old Japanese man was admitted to our hospital in October 2001 complaining of abdominal pain. Organomegaly and lymphadenopathy were not evident and ileus was diagnosed based on abdominal X-ray and laboratory findings. Abdominal surgery revealed an obstruction of the small intestinal ileocecum, and the lesion was surgically removed. Histological examination of the specimen revealed massive infiltration of mononuclear cells in the lamina propria, with a dimorphic population of plasma cells located in the superficial mucosa and centrocyte-like lymphocytes that had deeply proliferated into the mucosa (Fig. 1). Immuno-

${ }^{1}$ The First Department of Internal Medicine, Gifu University Graduate School of Medicine, Gifu, ${ }^{2}$ Department of Internal Medicine, ChunoKosei Hospital, Seki and ${ }^{3}$ Department of Immunopathology, Gifu University Graduate School of Medicine, Gifu

Received for publication August 14, 2007; Accepted for publication October 30, 2007

Correspondence to Dr. Hisashi Tsurumi, htsuru@cc.gifu-u.ac.jp 

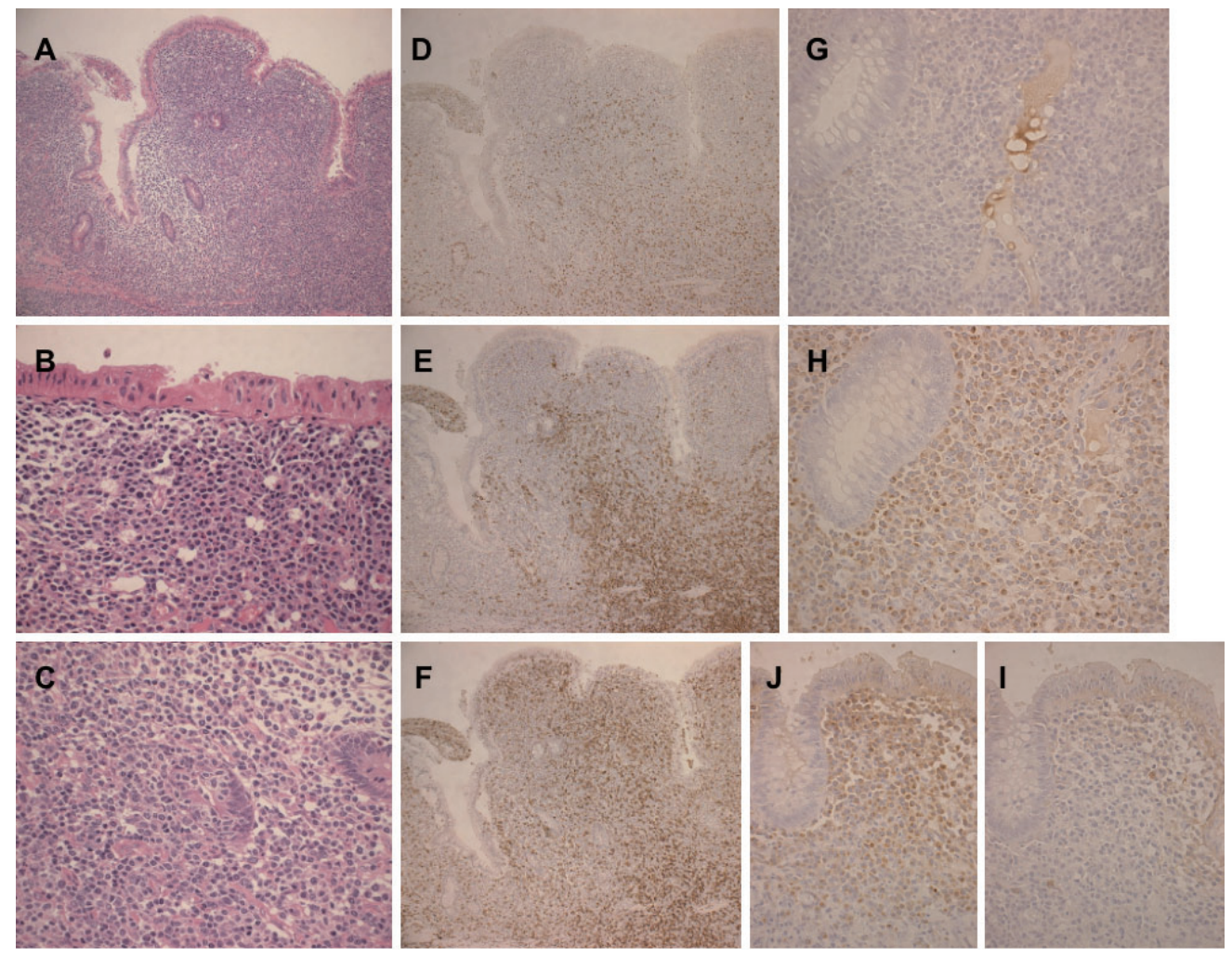

Figure 1. Histology of surgically resected intestinal specimens at onset. Massive infiltration of mononuclear cells in lamina propria, with dimorphic population of plasma cells located in superficial mucosa and centrocyte-like lymphocytes that had deeply proliferated into mucosa. Immunohistochemical staining of these specimens showed that infiltrated lymphocytes were positive for CD45RO+CD5+. $\mathrm{T}$ cells were dominant, but large atypical lymphocytes were CD20+MIB-1+B cell. Most plasmacytes were negative for MIB-1, but were monoclonal as they were positive for IgA and $\kappa$ chain and negative for IgG, IgM and $\lambda$ chain. Hematoxylin and Eosin staining (A), magnification $\times 50$; (B) interstitium and (C) submucosa, magnification $\times 200$; (D), MIB-1; (E) CD20; (F) CD45RO;

(G) IgG; (H and I) IgA; (J) IgG. Magnification D, E and F, ×50; G, H, I and J, ×200.

histochemical staining of these specimens showed that the infiltrated lymphocytes were CD45RO+CD5+ positive indicating $\mathrm{T}$ cell dominance, but $\mathrm{B}$ cells were large atypical $\mathrm{CD}$ 20+MIB-1+ lymphocytes. Most plasmacytes were MIB-1 negative and monoclonal as indicated by $\operatorname{IgA}$ and $\kappa$ chain positivity and $\operatorname{IgG}, \operatorname{IgM}$ and $\lambda$ chain negativity. Analysis of DNA extracted from the specimens revealed immunoglobulin heavy chain gene rearrangement by PCR, which confirmed a diagnosis of B-cell lymphoma (Fig. 2A). Giemsa and silver staining of the specimens and serological assays were all negative for Helicobacter pylori. Stool cultures were negative for Salmonella, Yersinia, Shigella, or Campylobacter. We could not confirm the absence of Campylobacter infection using PCR. Thus, IPSID was diagnosed based upon clinical, histopathological and immunological findings.

Six courses of THP-COP therapy (pirarubicin, cyclophosphamide, vincristine, and prednisolone) started immediately after diagnosis resulted in complete remission. Surgical resection left no apparent lesions, and complete remission was confirmed by abdominal and chest $\mathrm{CT}$ as well as Gascintigraphy. The patient remained in apparently good health for 16 months and was followed up as an outpatient. However, hypoalbuminemia was detected in May 2003. A sero-
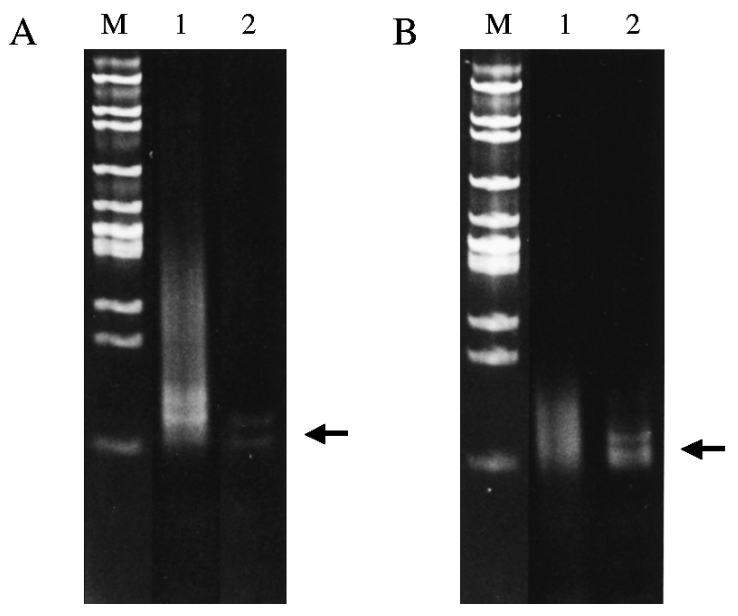

Figure 2. Analysis of DNA extracted from biopsy specimens show immunoglobulin heavy chain gene rearrangement by PCR confirming B-cell lymphoma (Fig. 2A) and rearrangement of T-cell receptor $\gamma$ gene (Fig. 2B). A: Immunoglobulin heavy chain gene rearrangement of small intestinal ileocecum detected by PCR. M, size marker; 1, negative control; 2, small intestinal ileocecum. B: T-cell receptor $\gamma$ gene rearrangement of duodenum detected by PCR. M, size marker; 1, negative control; 2 , duodenum. 

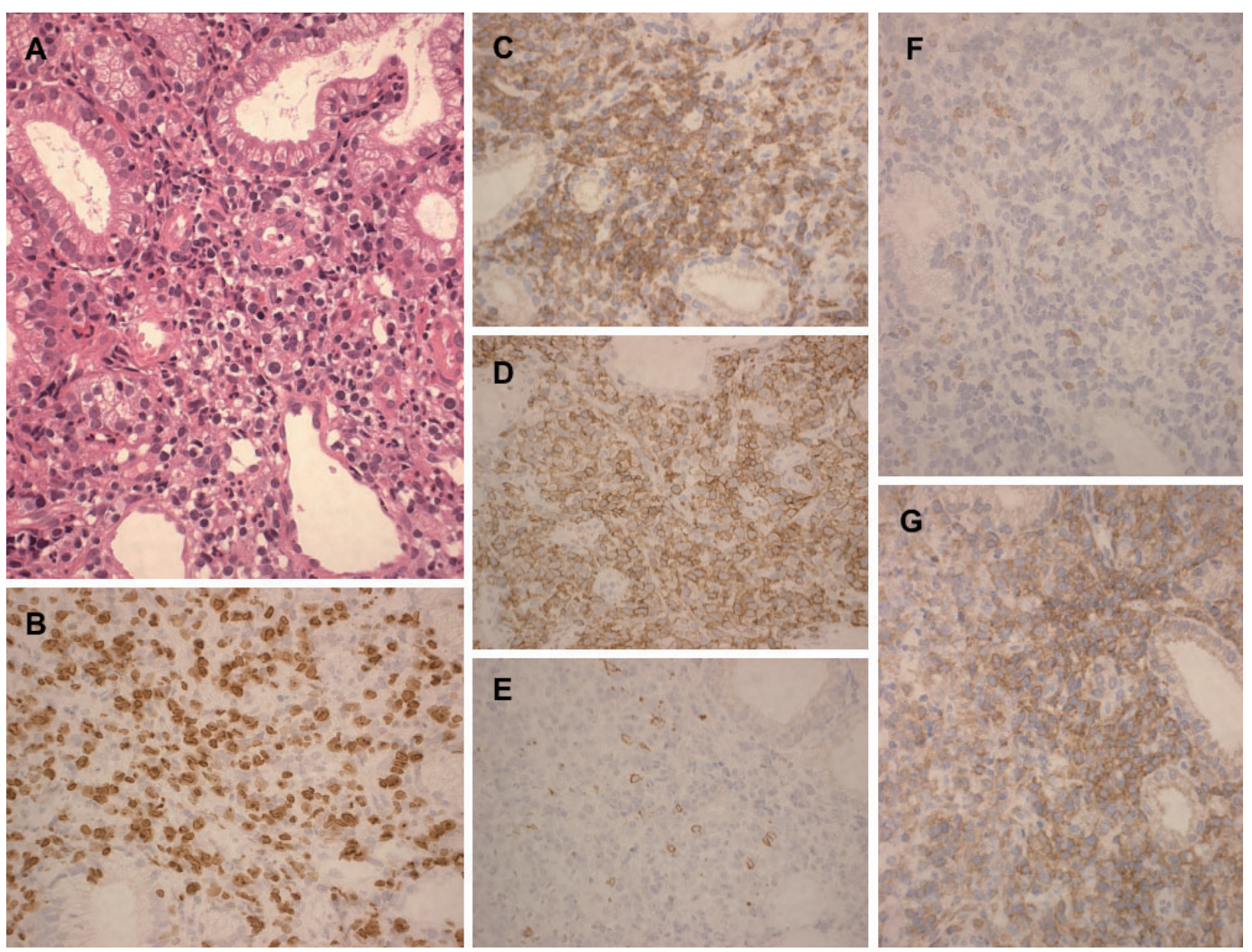

Figure 3. Histology of endoscopic duodenal biopsy specimens at progression. Medium to large lymphocytes have fine nuclear chromatin, indistinct nucleolus and little cytoplasm. Atypical lymphocytes were positive for CD 3, CD45RO, CD4, MIB-1 and negative for CD8, CD56, CD20. Hematoxylin and Eosin staining (A), magnification $\times 200$. Immunohistochemical staining for (B) MIB-1; (C) CD45RO; (D) CD3; (E) CD20; (F) CD8; (G) CD4. All magnification, ×200.

logical examination uncovered hypogammaglobulinaemia, but immunoelectrophoresis did not identify monoclonal immunoglobulin. Upper gastrointestinal (GI) endoscopy showed duodenal mucosal nodularity, a cobblestone appearance, and petechial hemorrhages. The gastric mucosa was unremarkable, and one fundic and two antral biopsy specimens were negative for $H$. pylori. Immunohistochemical staining of the duodenal biopsy specimens revealed that the lymphocyte infiltrate contained a few CD20 positive B cells, dominant CD45RO positive $\mathrm{T}$ cells and a few MIB-1 positive cells. Plasma cells were monoclonal and positive for $\operatorname{IgA}$, but negative for $\operatorname{IgG}$ and $\operatorname{IgM}$. The plasma cells included in normal mucosa were polyclonal and positive for $\kappa$ and $\lambda$ chains.

Colonoscopy and biopsy specimens revealed broad erosion of the terminal ileum, indicating that IPSID had relapsed. Barium X-rays of the small intestine showed disappearance of the Kerckring folds, dilation and partial stenosis of the proximal ileum. An abdominal CT scan revealed splenomegaly, swelling of the mesenteric lymph nodes, and a thickened ileum wall. Gallium-scintigraphy revealed a hot spot on the left lower abdomen and HAS-scintigraphy revealed protein leakage from the colon. These findings all indicated that the hypoalbuminemia was induced by protein loss from the colon due to the relapsed IPSID. We started immediate salvage therapy with R-P-IMVP16/CBDCA (rituximab, methylprednisolone, ifosfamide, methotrexate, etoposide, and carboplatin). This strategy temporarily improved the hypoalbuminemia. This treatment was done by two courses, but this returned accompanied by fever three months later. Minocycline did not improve the fever and diarrhea. Although we started salvage therapy with R-CdA (rituximab and cladribine) therapy, fever and diarrhea were continued. To confirm his lesion, we performed upper GI endoscopy.

Upper GI endoscopy revealed more duodenal mucosal nodularity and erosion. Immunohistochemical staining of the biopsy specimens uncovered T-cell lymphoma with diffuse and dense infiltration of atypical lymphocytes. Such medium to large lymphocytes had fine nuclear chromatin, an indistinct nucleolus, little cytoplasm and were positive for CD 3, CD45RO, CD4, MIB-1 and negative for CD8, CD56, CD20 (Fig. 3). We established a diagnosis of peripheral T-cell lymphoma, unspecified. A PCR analysis of DNA extracted from the duodenum revealed $\mathrm{TCR} \gamma$ chain gene rearrangement that confirmed the diagnosis of T-cell lymphoma (Fig. 2B). Chest and abdominal CT revealed no other lesion. We abandoned the continuance of chemotherapy as the general condition of the patient had degenerated. He died of sepsis in December 2004, two months after the last chemotherapy. 


\section{Discussion}

Immunoproliferative small intestinal disease is a form of lymphoma that arises in small intestinal mucosa-associated lymphoid tissue (MALT) and it is associated with the expression of a monotypic truncated immunoglobulin $\alpha$ heavy chain without an associated light chain. Early-stage disease responds to antibiotics, suggesting a bacterial origin. The association of Campylobacter jejuni with IPSID is similar to the link between $H$. pylori infection and gastric MALT lymphoma $(8,9)$. Understanding the association between $C$. jejuni and IPSID might lead to improvements in the diagnosis, management, and prevention of this disease, at least in a subgroup of patients (10). The incidence of the IPSID is more unusual in Japan than in Europe. The reason is not clear, but the morbidity of IPSID might be connected with the prevalence of $C$. jejuni infection, while the precise infection rate remains unclear in Japan.

Helicobacter pylori plays a role in the pathogenesis of the primary gastric low grade B-cell lymphoma associated with MALT. Treatment for $H$. pylori can cause lymphoma to regress $(8,11,12)$. Given the gastric extension of IPSID and the phenotypic similarities between IPSID and $H$. pyloriassociated gastric MALT lymphoma $(13,14), H$. pylori eradication from at least one patient with IPSID has resulted in lymphoma regression (15). Because of frequent small intestinal bacterial overgrowth, the recommended treatment for early stage IPSID has been broad-spectrum antibiotics, with or without corticosteroid. This therapy has occasionally resulted in temporary clinical and/or histological or immunochemical remission, and sometimes, durable relief (16-18). However, we applied combination chemotherapy for our patient because his condition was either in a state of progression or relapse at the times of presentation.

Our patient became complicated with duodenal $\mathrm{T}$ cell lymphoma about 2 years after onset. Coexistent B- and Tcell lymphomas are unusual. A review of the literature could not find any case report of IPSID complicated with T-cell lymphoma of the digestive tract. The relationship between the components of discordant and composite lymphomas of B-cell and T-cell lineage is unclear. One possibility is that the components are unrelated and coincidental. Medeiros and Stetler-Stevenson have proposed possible mechanisms for the development of two lymphomas in one patient (19). They might result from malignant transformation of a stem cell with the capacity to differentiate along B- and T-cell lineages or with a shared inherent predisposition. Exposure to common carcinogens could separately transform B- and T-cell progenitors and factors secreted by the initial neoplastic cell population could play a role in the development of a second tumor. Our patient was compromised because of preceding chemotherapy and his original underlying condition.

We postulate that systemic or local disruption of the immunomechanism induced by IPSID contributed to the onset of a new T-cell lymphoma (TCL) in the duodenum with IPSID whereas other lymph nodes remained intact.

\section{References}

1. Khojasteh A, Haghshenass M, Haghighi P. Current concepts immunoproliferative small intestinal disease. A "Third-World lesion". N Engl J Med 308: 1401-1405, 1983.

2. Rambaud JC. Small intestinal lymphomas and alpha-chain disease. Clin Gastroenterol 12: 743-746, 1983.

3. Isaacson PG. Gastrointestinal lymphoma. Hum Pathol 25: 10201029, 1994.

4. Jaffe E, Harris NL, Stein H, Vardiman JW, Eds. In: Tumours of Hematopoietic and Lymphoid Tissues. IARC Press, Lyon, 2001.

5. Seligmann M, Danon F, Hurez D, Mihaesco E, Preud'homme JL. Alpha-chain disease: a new immunoglobulin abnormality. Science 162: 1396-1397, 1968.

6. Salem P, el-Hashimi L, Anaissie E, et al. Non-Hodgkin's lymphomas in the Middle East. A study of 417 patients with emphasis on special features. Cancer 58: 1162-1166, 1986.

7. Hibi T, Asakura H, Kobayashi K, et al. Alpha heavy chain disease lacking secretory alpha chain, with cobblestone appearance of the small intestine and duodenal ulcer demonstrated by endoscopy. Gut 23: 422-427, 1982

8. Wotherspoon AC, Doglioni C, Diss TC, et al. Regression of primary low-grade B-cell gastric lymphoma of mucosa-associated lymphoid tissue type after eradication of Helicobacter pylori. Lancet 342: 575-577, 1993.

9. Hussell T, Isaacson PG, Crabtree JE, Spencer J. The response of cells from low-grade B-cell gastric lymphomas of mucosaassociated lymphoid tissue to Helicobacter pylori. Lancet 342: 571-574, 1993.

10. Lecuit M, Abachin E, Martin A, et al. Immunoproliferative small intestinal disease associated with Campylobacter jejuni. N Engl J Med 350: 239-248, 2004.

11. Bayerdorffer E, Neubauer A, Rudolph B, et al. Regression of primary gastric lymphoma of mucosa-associated lymphoid tissue type after cure of Helicobacter pylori infection. MALT Lymphoma Study Group. Lancet 345: 1591-1594, 1995.

12. Roggero E, Zucca E, Pinotti G, et al. Eradication of Helicobacter pylori infection in primary low-grade gastric lymphoma of mucosa-associated lymphoid tissue. Ann Intern Med 122: 767769, 1995.

13. Isaacson $P$, Wright $D H$. Malignant lymphoma of mucosaassociated lymphoid tissue. A distinctive type of B-cell lymphoma. Cancer 52: 1410-1416, 1983.

14. Isaacson PG, Dogan A, Price SK, Spencer J. Immunoproliferative small-intestinal disease. An immunohistochemical study. Am J Surg Pathol 13: 1023-1033, 1989.

15. Fischbach W, Tacke W, Greiner A, Konrad H. Muller-Hermelink. Regression of immunoproliferative small intestinal disease after eradication of Helicobacter pylori. Lancet 349: 31-32, 1997.

16. Matuchansky C, Cogne M, Lemaire $M$, et al. Nonsecretory alphachain disease with immunoproliferative small-intestinal disease. $\mathrm{N}$ Engl J Med 320: 1534-1539, 1989.

17. Gilinsky NH, Novis BH, Wright JP, Dent DM, King H, Marks IN. Immunoproliferative small-intestinal disease: clinical features and outcome in 30 cases. Medicine (Baltimore) 66: 438-446, 1987.

18. O'Keefe SJ, Winter TA, Newton KA, Ogden JM, Young GO, Price SK. Severe malnutrition associated with alpha-heavy chain disease: response to tetracycline and intensive nutritional support. 
DOI: $10.2169 /$ internalmedicine.47.0524

Am J Gastroenterol 83: 995-1001, 1988.

19. Medeiros LJ, Stetler-Stevenson MA. Composite B-cell and T-cell lymphoma: coincidental occurrence or related neoplasms. Am J Clin Pathol 98: 387-389, 1992.

(C) 2008 The Japanese Society of Internal Medicine http://www.naika.or.jp/imindex.html 